\title{
INVESTIGATION OF MECHANICAL PROPERTIES OF POLYIMIDE FILMS UNDER THE INFLUENCE OF LABORATORY-SIMULATED SPACE FACTORS
}

\author{
V.A. Lototskaya ${ }^{1 *}$, L.F. Yakovenko ${ }^{1}$, E.N. Aleksenko ${ }^{1}$, V.A. Velichko ${ }^{1}$, I.P. Zaritskiy ${ }^{1}$, \\ V.V. Abraimov ${ }^{2}$, Wen Zhu Shao ${ }^{2}$, Liu Hai ${ }^{2}$ \\ ${ }^{1}$ B. Verkin Institute for Low Temperature Physics and Engineering of NAS of Ukraine \\ Prospect Nauky, 47, Kharkov, 61103, Ukraine \\ *E-mail: lototskaya@ilt.kharkov.ua, https://orcid.org/0000-0001-8766-3154 \\ ${ }^{2}$ Harbin Institute of Technology \\ Harbin, the People's Republic of China \\ Received June 19, 2018; revised August 9, 2018; accepted August 28, 2018
}

In work the mechanical properties of polyimide films analogue kapton-H (manufactures of the People's Republic of China) by thickness 75 microns are studied in conditions of uniaxial stretching at temperature $293 \mathrm{~K}$ after influence of space factors - a separate and joint irradiation by protons and electrons with energy $\mathrm{E}=160 \mathrm{keV}$ and fluence (the total flow of particles with incident on the samples) $\mathrm{F}=10^{16} \mathrm{~cm}^{-2}$. The limit of the forced elasticity, the ultimate strength, the total strain before fracture and the contributions to the total deformation related to the elastic deformation occurring in the linear stage, the total forced elastic and irreversible deformation that contribute to the overall deformation of the samples at the nonlinear stage are determined. The total forced elastic deformation consists of a highly elastic deformation, reversible at the test temperature, and delayed elastic deformation. After exposure to irradiation, an increase in the limit of the forced elasticity of the films by $5-11 \%$, a decrease in the ultimate strength by $10-14 \%$, and a reduction in the total deformation by $20-28 \%$ were found. The maximum change in all mechanical characteristics occurs under the influence of proton irradiation. It is established that the decrease in the total deformation of irradiated films is mainly due to a $80 \%$ reduction in the contribution of irreversible deformation. The contribution of the total forced elastic deformation of the polyimide film practically does not change after irradiation, which has important scientific and applied significance.

KEY WORDS: polyimides, space factors, limit of forced elasticity, ultimate strength, deformability

\section{ДОСЛІДЖЕННЯ МЕХАНІЧНИХ ВЛАСТИВОСТЕЙ ПОЛІМІДНИХ ПЛІВОК ПІД ВПЛИВОМ ФАКТОРІВ КОСМОСУ, ЩО ІМІТОВАНІ ЛАБОРАТОРНО \\ В.О. Лотоцька ${ }^{1}$, Л.Ф. Яковенко ${ }^{1}$, С.М. Алексенко ${ }^{1}$, М.І. Величко ${ }^{1}$, І.П.Зарицький ${ }^{1}$} B.B. Абраiмов ${ }^{2}$, Wen Zhu Shao ${ }^{2}$, Liu Hai ${ }^{2}$

${ }^{l}$ Фізико-технічний інститут низьких температур ім. Б.І. Вєркіна НАН Украӥни

пр. Науки, 47, м. Харків, 61103, Україна

${ }^{2}$ Харбінський Політехнічний інститут м. Харбін, КНР

У роботі вивчені механічні властивості поліімідних плівок типу kapton-Н (виробництва КНР) завтовшки 75 мкм в умовах одновісного розтягування при температурі 293 К після дії чинників космічного простору - роздільного і спільного опромінення протонами і електронами з енергією $\mathrm{E}=160$ кэВ і флюенсом (повним потоком частинок, що падають на зразки) $10^{16} \mathrm{~cm}^{-2}$. Визначені границя вимушеної еластичності, межа міцності, сумарна деформація до руйнування і вклади в сумарну деформацію, пов'язані з пружною деформацією, яка відбувається на лінійній стадії, повною вимушеною еластичною $\mathrm{i}$ незворотною деформацією, які вносять свій внесок в загальну деформацію зразків на нелінійної стадії. Повна вимушена еластична деформація складається з високоеластичної деформації, оборотної при температурі випробування, і затриманої еластичної деформації. Після впливу опромінення виявлено збільшення границі вимушеної еластичності плівок на 5-11\%, зниження межі міцності на 10-14\% і зменшення сумарної деформації на 20-28\%. Максимальна зміна всіх механічних характеристик відбувається під впливом опромінення протонами. Встановлено, що зниження сумарної деформації опромінених плівок відбувається, в основному, за рахунок скорочення на 80\% вкладу необоротної деформації. Внесок повної вимушеної еластичної деформації плівки полиимида практично не змінюється після опромінення, що має важливе наукове і прикладне значення.

КЛЮЧОВІ СЛОВА: полііміди, фактори космічного простору, границя змушеної еластичності, межа міцності, деформованість

\section{ИССЛЕДОВАНИЕ МЕХАНИЧЕСКИХ СВОЙСТВ ПОЛИИМИДНЫХ ПЛЕНОК ПРИ ВОЗДЕЙСТВИИ ФАКТОРОВ КОСМОСА, ИМИТИРУЕМЫХ ЛАБОРАТОРНО \\ В.А. Лотоцкая ${ }^{1}$, Л.Ф. Яковенко ${ }^{1}$, Е.Н. Алексенко ${ }^{1}$, Н.И. Величко ${ }^{1}$, И.П. Зарицкий ${ }^{1}$, в.в. Абраимов ${ }^{2}$, Wen Zhu Shao' ${ }^{2}$ Liu Hai ${ }^{2}$ \\ ${ }^{l}$ Физико-технический институт низких температур им. Б.И.Веркина НАН Украины,} пр. Науки, 47, г. Харьков, 61103, Украина

${ }^{2}$ Харбинский Политехнический институт, г. Харбин, КНР

В работе изучены механические свойства полиимидных пленок типа kapton-Н (производства КНР) толщиной 75 мкм в условиях одноосного растяжения при температуре 293 К после воздействия факторов космического пространства раздельного и совместного облучения протонами и электронами с энергией $\mathrm{E}=160$ кэВ и флюенсом (полным потоком частиц, падающих на образцы) $10^{16} \mathrm{~cm}^{-2}$. Определены предел вынужденной эластичности, предел прочности, суммарная деформация до разрушения и вклады в суммарную деформацию, связанные с упругой деформацией, происходящей на линейной стадии, (C) Lototskaya V.A., Yakovenko L.F., Aleksenko E.N., Velichko V.A.,

Zaritskiy I.P., Abraimov V.V., Wen Zhu Shao, Liu Hai, 2018 
полной вынужденной эластической и необратимой деформацией, которые вносят свой вклад в общую деформацию образцов на нелинейной стадии. Полная вынужденная эластическая деформация состоит из высокоэластической деформации, обратимой при температуре испытания, и задержанной эластической деформации. После воздействия облучения обнаружено увеличение предела вынужденной эластичности пленок на 5-11\%, снижение предела прочности на $10-14 \%$ и уменьшение суммарной деформации на 20-28\%. Максимальное изменение всех механических характеристик происходит под воздействием облучения протонами. Установлено, что снижение суммарной деформации облученных пленок происходит, в основном, за счет сокращения на $80 \%$ вклада необратимой деформации. Вклад полной вынужденной эластической деформации пленки полиимида практически не изменяется после облучения, что имеет важное научное и прикладное значение.

КЛЮЧЕВЫЕ СЛОВА: полиимиды, факторы космического пространства, предел вынужденной эластичности, предел прочности, деформируемость

При создании космических аппаратов (КА) нового поколения широкое применение получили полиимидные материалы (типа ПМ-А, kapton-H), благодаря уникальным физико-химическими свойствам: высокой химической, термической и радиационной стойкости, превосходным физико-механическим характеристикам [1]. Пленки указанных материалов используются в качестве: экранно-вакуумной теплоизоляции (ЭВТИ) и терморегулирующих покрытий (ТРП), обеспечивающих заданный тепловой режим КА, отражающих систем (космических зеркал), разного типа антенн КА, промежуточных (изолирующих) слоев солнечных батарей КА. Так например, при создании новейшего космического телескопа ВЭББ с диаметром основного зеркала $6,5 \mathrm{M}$, для отражения потока солнечного излучения будут использованы пять слоев полиимидных пленок kapton-Н толщиной 25 и 50 мкм с площадью $\approx 900 \mathrm{M}^{2}$.

В космическом пространстве на материалы и элементы космических аппаратов одновременно и поочередно воздействует целый ряд экстремальных факторов, таких, как: глубокий вакуум $\left(\mathrm{P} \approx 10^{-4}-10^{-5}\right.$ Па), активные частицы плазмы «солнечного ветра», электромагнитное излучение Солнца (в интервале длин волн $\lambda=1-2500$ нм), ионизирующие излучения (потоки протонов и электронов радиационных поясов Земли в широком интервале энергий частиц $\mathrm{E}=30$ кэВ -10 МэВ), атомарный кислород (с энергией частиц $\mathrm{E}=5$ эВ), продукты собственной внешней атмосферы космического аппарата, термоциклирование (в интервале температур $\mathrm{T}=-150^{\circ} \mathrm{C} \ldots+150^{\circ} \mathrm{C}$ ), невесомость и другие факторы. Изучение закономерностей и специфики поведения полимерных материалов при воздействии комплекса и отдельных факторов космического пространства (ФКП) является одной из важных задач космического материаловедения.

Целью настоящей работы являлось исследование закономерностей деформации и разрушения полиимидных пленок kapton - Н (производства КНР) после воздействия факторов космического пространства (ФКП) при комнатной температуре. В работе использовали метод механических испытаний - одноосное растяжение при $\mathrm{T}=293 \mathrm{~K}$ и скорости деформации $7 \cdot 10^{-4} \mathrm{c}^{-1}$. Воздействие факторов космоса на исследуемые материалы было проведено путем раздельного и совместного облучения протонами и электронами с энергией частиц $\mathrm{E}=160 \kappa э В$.

\section{МЕТОДИКА ЭКСПЕРИМЕНТА}

Объектами исследования являлись образцы из термопластичной пленки ароматического полиимида поли -4,4'-дифиниленоксидпиромеллитимида - толщиной 75мкм. Механические свойства указанной пленки (производства КНР) в исходном состоянии изучены в работе [2].

Образцы для испытания при одноосном растяжении (рис.1) получали с помощью специального штампа. Ось растяжения совпадала с направлением протяжки пленки. Форма и размеры образца близки образцу типа 1 по ГОСТ 11262-80, который допускается к использованию для испытаний на растяжение пленочных полимерных образцов (ГОСТ 14236-81). Крепление образца осуществляли в специальных захватах. Захват состоит из ролика, вокруг которого огибается лопатка образца и двух прижимов, захватывающих ролик с лопаткой.

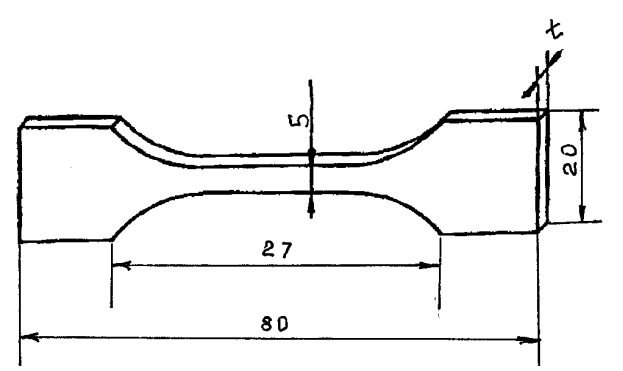

Рис.1. Форма образца для испытаний на растяжение

Механические свойства исходных образцов, подвергнутых воздействию ФКП, исследовали при комнатной температуре на воздухе (293 К). Деформирование образцов в условиях одноосного растяжения проводили на разрывной машине FPZ-100/1 с низкотемпературной приставкой, созданной во ФТИНТ [3], при скорости 
перемещения активного штока $\mathrm{V}_{\text {деф}}=0,85 \mathrm{Mм} /$ мин, что соответствовало скорости пластической деформации материалов $\dot{\varepsilon}=7 \cdot 10^{-4} \mathrm{c}^{-1}$ ( $\dot{\varepsilon}=\mathrm{V}_{\text {деф }} / \mathrm{L}_{\text {о, }}$ где $\mathrm{L}_{\mathrm{o}}$ - исходная рабочая длина образца).

В процессе деформирования записывали диаграмму растяжения в координатах «нагрузка Р - удлинение $\Delta \mathrm{L} »$, из которой определяли следующие механические характеристики пленок: условный предел вынужденной эластичности, соответствующий напряжению, при котором высокоэластическая деформация составляет $1 \%$, $\sigma_{\mathrm{B}}=\mathrm{P}_{1 \%} / \mathrm{S}_{\mathrm{o}}$; предел прочности пленок: (напряжение разрыва образца) $\sigma_{\mathrm{p}}=\mathrm{P}_{\mathrm{p}} / \mathrm{S}_{\mathrm{o}}$, где $\mathrm{S}_{\mathrm{o}}-$ начальное сечение образца; общее удлинение $\Delta \mathrm{L}_{\text {общ, }}$ соответствующее моменту разрыва образца; удлинение $\Delta \mathrm{L}_{\text {упр, }}$ соответствующее упругому участку кривой. Кроме обратимого (упругого) удлинения $\Delta \mathrm{L}_{\text {упр, }}$ связанного с

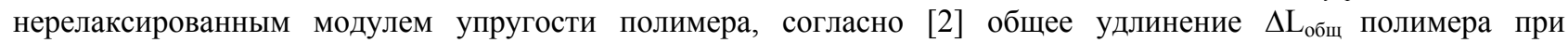

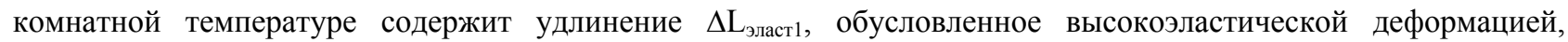

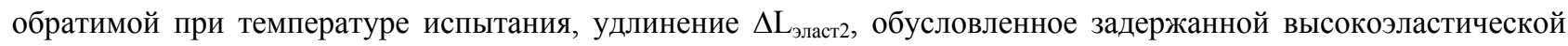

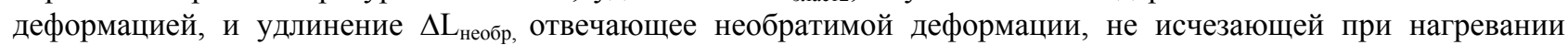

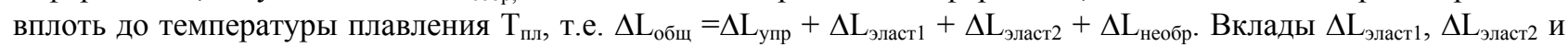
$\Delta \mathrm{L}_{\text {необр }}$ определяли как в [2] на исходных образцах . Нормируя полученные значения $\Delta \mathrm{L}$ на величину исходной рабочей длины образца $\mathrm{L}_{0}$, получали соответствующие значения относительной деформации.

Bсе указанные механические характеристики представлены далее как средние значения по результатам измерений на 6 образцах, как в исходном состоянии, так и после каждого вида облучения.

Воздействие ФКП (имитируемые лабораторно) на исследованные полиимидные пленки проводили в комплексном имитаторе факторов космоса КИФК, созданном во ФТИНТ НАН Украины (рис.2) [4].

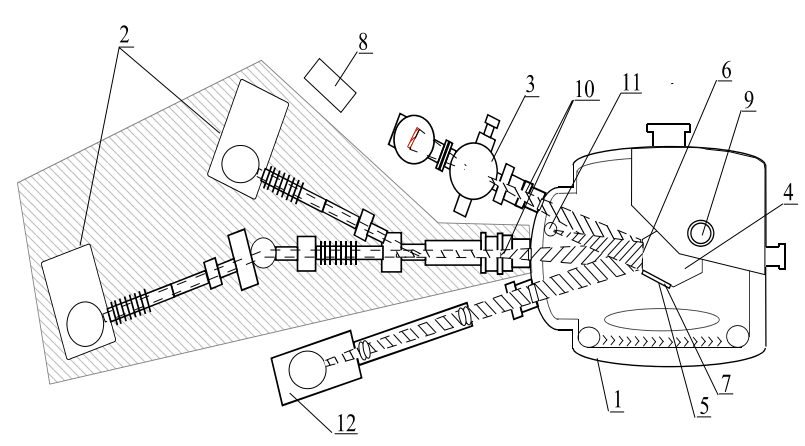

A

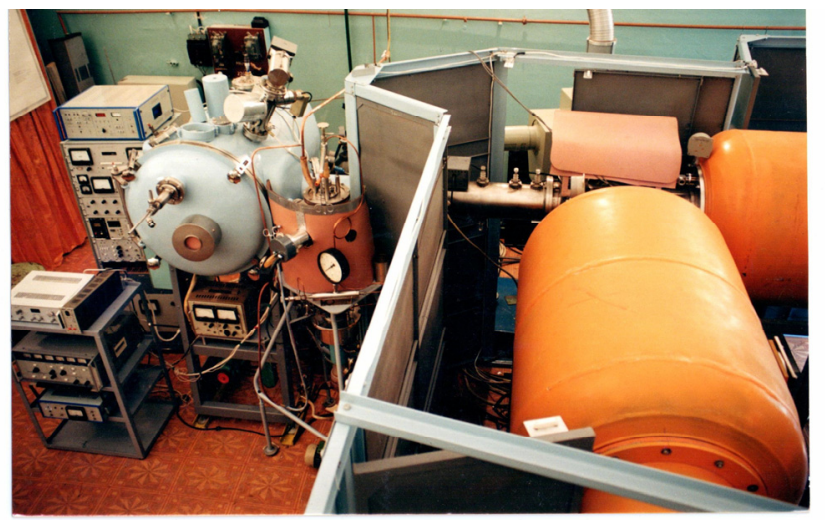

6

Рис.2. Имитатор КИФК

a - схема, б - общий вид имитатора КИФК, эксплуатируемого в ФТИНТ им. Б.И. Веркина НАН Украины

Комплексный имитатор КИФК (рис.2) состоит из следующих основных систем: вакуумной камеры (1) с системами криогенной и вакуумной откачки, ускорителя протонов и электронов (2) с совмещенными пучками частиц, источника вакуумного ультрафиолетового (ВУФ) и ультрамягкого рентгеновского (УМР)-излучения (3) со специальной вакуумной камерой для исследования физико-механических свойств материалов в поле ВУФизлучения, источника искусственного заатмосферного Солнца типа ИС-160 (12), пультов управления комплексным имитатором с системами автоматического измерения свойств материалов на базе персональных компьютеров, а также радиационной защиты персонала от рентгеновского и гамма-излучений, которое возникает при работе ускорителей электронов и протонов. Радиационная защита изготовлена из специальной рентгенозащитной резины с добавлением окислов редкоземельных материалов и включает в себя: защитное ограждение ускорителей протонов и электронов, а также радиационной защиты на поверхности вакуумной камеры (1) и остальных источниках излучения имитатора КИФК.

В криогенно-вакуумной камере имитатора КИФК одновременно имитируются 8 основных экстремальных факторов космического пространства:

1 и 2. Потоки протонов (1) и электронов (2) радиационных поясов Земли с энергией частиц $\mathrm{E}=30-200$ кэВ (площадь облучения $\mathrm{S}=100 \mathrm{~cm}^{2}$; ток пучков протонов и электронов $\mathrm{I}=0,5-50$ мкА ). Имитация протонов и электронов производится на совмещенных пучках частиц при их нормальном падении на материалы КА.

3. Электромагнитное излучение заатмосферного Солнца в интервале длин волн: $\lambda=200-2500$ нм с интенсивностью излучения $\mathrm{J}_{\mathrm{C}}=0,14 \div 0,28 \mathrm{BT} / \mathrm{cm}^{2}$ и площадью облучения $\mathrm{S}=100 \mathrm{~cm}^{2}$.

4. Вакуумное ультрафиолетовое (ВУФ) и ультрамягкое рентгеновское (УМР)- излучения Солнца в диапазоне длин волн $\lambda=1,24-200$ нм с интенсивностью излучения $(0,01 \div 3) \cdot 10^{-4} \mathrm{Bт} / \mathrm{cm}^{2}$ и площадью облучения $\varnothing=120 \mathrm{~cm}^{2}$. Спектр излучения ВУФ-имитатора максимально приближен к спектру излучения Солнца в указанном диапазоне длин волн. 
5. Глубокий вакуум космического пространства $\mathrm{P}=10^{-4}-10^{-5}$ Па.

6. Изменение температуры материалов, элементов и систем КА (термоциклирование) в интервалах температур $\Delta \mathrm{T}_{1}=77-400 \mathrm{~K}$ и $\Delta \mathrm{T}_{2}=4,2-400 \mathrm{~K}$ в глубоком вакууме $\left(\mathrm{P}=10^{-4}-10^{-5}\right.$ Па).

7. Чернота космического пространства: $\varepsilon \approx 0,95-0,97$.

8. Низкий коэффициент возврата частиц: $\mathrm{Z}_{0} \rightarrow 0$.

$\mathrm{B}$ настоящей работе образцы подвергались воздействию моноэнергетических потоков корпускулярного излучения со средней энергией $\mathrm{E}=160$ кэВ. Полный поток частиц, падающих на образцы (флюенс), составлял

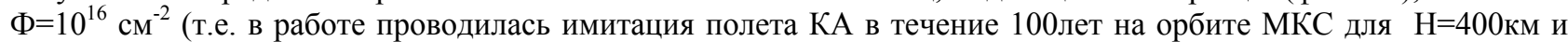
полета КА на геостационарной орбите $\mathrm{H}=36000$ км в течение 10 лет). Частицы (протоны и электроны) со

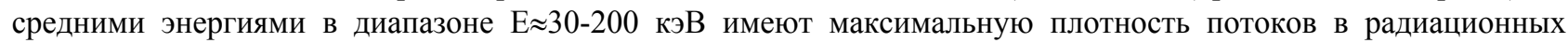
поясах Земли. Причем для этого диапазона энергий средние пробеги протонов лежат в интервале длин $\xi_{\mathrm{P}}=$ 0,5-2 мкм, а средние пробеги электронов имеют величину $\xi_{\mathrm{e}} \approx 80-100$ мкм, т.е. все падающие частицы поглощаются в поверхностных слоях материала. При указанных флюенсах поглощенные образцами дозы имеют весьма высокие значения: Д $\approx 10^{10}-10^{11}$ рад, это может привести к существенной деградации основных физико-механических свойств материала, а в некоторых случаях - к их полному разрушению, даже в отсутствии механических напряжений.

\section{РЕЗУЛЬТАТЫ ЭКСПЕРИМЕНТА И ИХ ОБСУЖДЕНИЕ}

На рис. 3 представлены типичные кривые «напряжение (б)-деформация $(\varepsilon) »$ исследованных образцов полиимидных пленок: исходных образцов (1), образцов, после раздельного облучения электронами (2) и протонами (3), а также образцов после совместного облучения протонами и электронами флюэнсом $\Phi=10^{16}$ ч/см ${ }^{2}(4)$. Кривые $\sigma$ - $\varepsilon$ образцов как в исходном состоянии, так и после облучения имеют две стадии линейную и нелинейную.

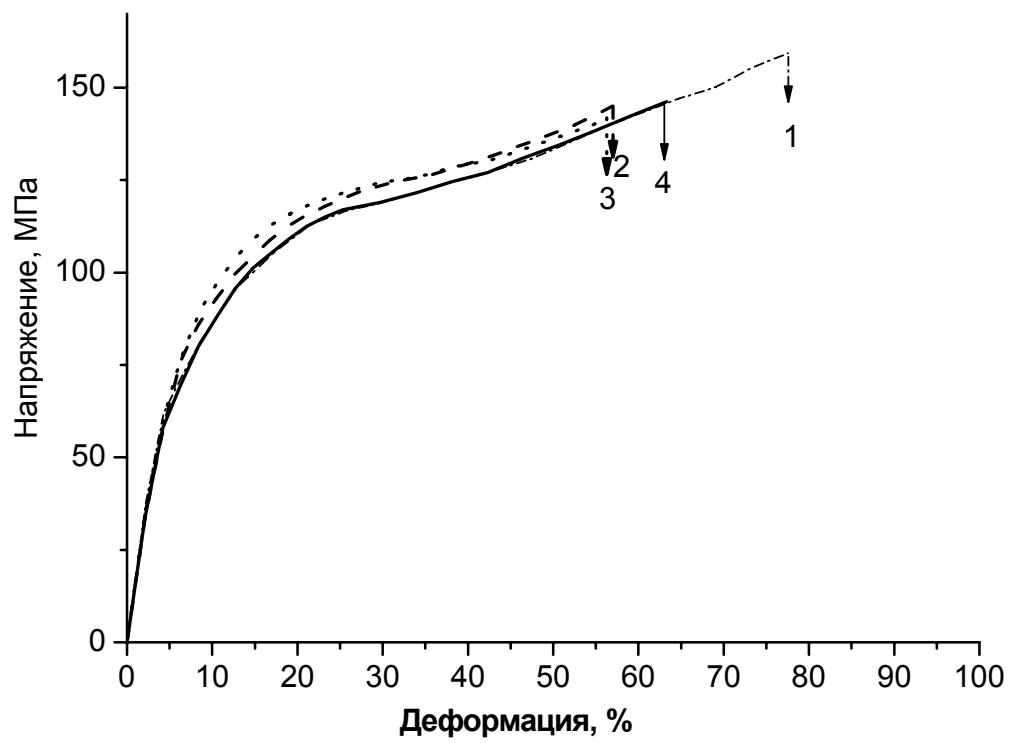

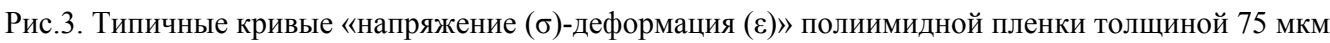

1 - в исходном состоянии, 2 - после облучения электронами, 3 - протонами, 4 - совместно электронами и протонами при $\mathrm{T}=293 \mathrm{~K}$ и скорости деформации $7 \cdot 10^{-4} \mathrm{c}^{-1}$

В области упругих деформаций (т.е. при которых выполняется закон Гука: $\sigma=$ Еє, где Е-модуль Юнга материала), деформирующие напряжения имеют обратимый характер и диаграммы $\sigma(\varepsilon)$ при нагружении и разгрузке совпадают. Если деформировать облученный образец на нелинейной стадии до напряжения вблизи предела прочности $\sigma_{\mathrm{p}}$, то при последующей разгрузке будет наблюдаться гистерезис хода кривой $\sigma(\varepsilon)$ и часть деформации, протекающей на нелинейной стадии будет являться обратимой высокоэластической при температуре испытания. Существуют также вклады необратимой и задержанной высокоэластической деформации, которые определялись по методике, описанной в работе [2].

Из рис.3 видно, что облучение полиимидов протонами и электронами флюенсом $10^{16} \mathrm{~cm}^{-2}$, (что соответствует 10 годам полета КА на геостационарной орбите $\mathrm{H=36000км} \mathrm{и} 100$ годам полета КА на орбите МКС при $\mathrm{H}=400$ км) приводит к упрочнению материала, т.е. к увеличению на $5-11 \%$ деформирующих напряжений вдоль всей кривой $\sigma(\varepsilon)$ и, соответственно, к увеличению предела вынужденной эластичности. Этот результат важен с практической точки зрения и выгодно отличает этот тип полимера от других линейных полимеров, исследовавшихся с целью их использования в конструкциях космических аппаратов. Отметим, что исследование полимеров, типа полиэтилена, фторопласта, майлара, проведенное в работах [7-10] показало, что 
их облучение протонами, электронами, ВУФ-излучением и потоками заатмосферного Солнца приводило к разупрочнению материалов, т.е. к уменьшению уровня деформирующих напряжений на 40-45\% . В работе [5] показано, что под влиянием протонов и электронов с энергией частиц $\mathrm{E}=160$ кэВ и флюенсе $10^{16} \mathrm{~cm}^{-2}$ политетрафторэтилен (майлар) разрушался без приложения к нему внешних механических напряжений.

Средние значения механических характеристик исследованных полиимидных пленок после воздействия ФКП (электронов и протонов с энергией $\mathrm{E}=160$ кэВ и флюенсом $\Phi=10^{16} \mathrm{~cm}^{-2}$ ) представлены на рис.4. Упрочняющий эффект на пределе вынужденной эластичности, обнаруженный авторами ранее [5] на пленках производства РФ (толщиной 40мкм) при совместном облучении протонами и электронами, в данных пленках значительно меньше. Максимальное увеличение предела вынужденной эластичности $\sigma_{\mathrm{B}}$ на $11 \%$ (в настоящих исследованиях) наблюдалось при облучении пленок полиимида протонами. Напряжение разрушения $\sigma_{\mathrm{p}}$ и суммарная

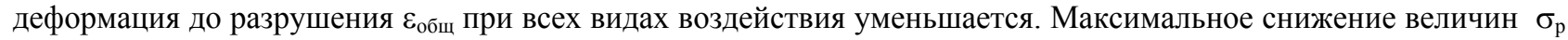

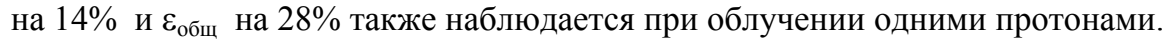

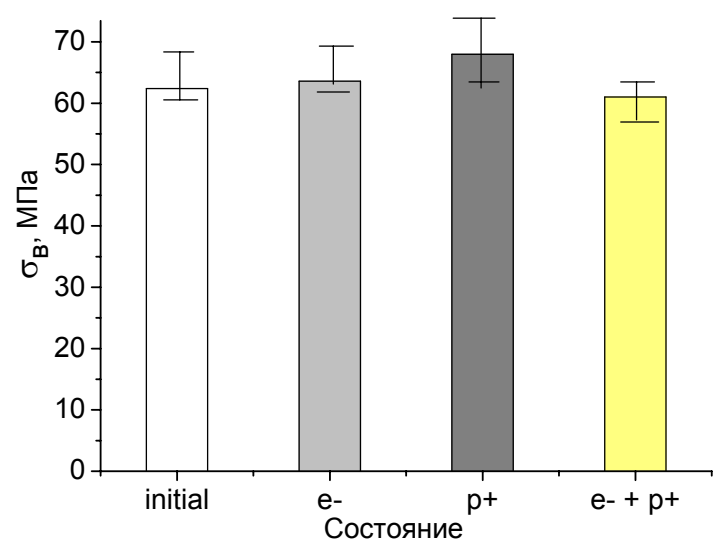

a)

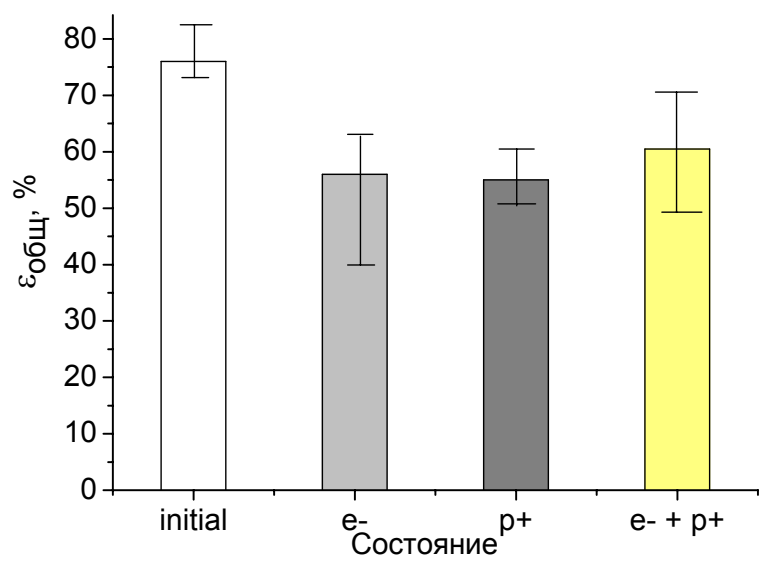

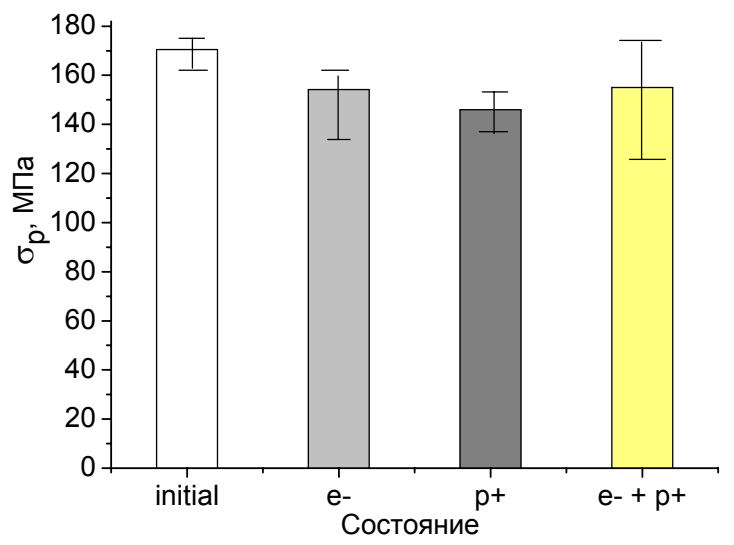

б)

B)

Рис. 4. Средние значения механических характеристик:

а) предел вынужденной эластичности, б) напряжение разрушения, в) суммарная деформация до разрушения образцов полиимидной пленки толщиной 75 мкм при комнатной температуре в исходном состоянии и после воздействия ФКП

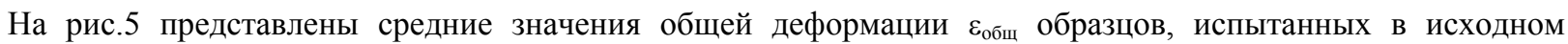
состоянии и после воздействия ФКП и отдельных вкладов в нее: вклада обратимой при температуре испытания высокоэластической деформации $\varepsilon_{\text {эласт1 }}$, полной вынужденной эластической деформации (обратимой $\varepsilon_{\text {эласт1 }}+$

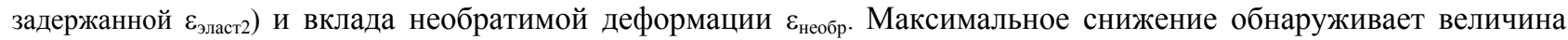
необратимой деформации, достигая $80 \%$ при облучении протонами. Максимальное снижение обратимой при

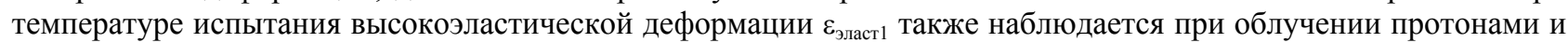
достигает $30 \%$. Снижение полной вынужденной эластической деформации (обратимой $\varepsilon_{\text {эласт }}+$ задержанной $\varepsilon_{\text {эласг2 }}$ ) наименьшее по сравнению другими вкладами и колеблется от $13 \%$ при облучении одними протонами до $5 \%$ при совместном облучении электронами и протонами. 
Образцы пленок, облученные электронами, претерпевают слабое окрашивание(потемнение), которое релаксирует через несколько часов после облучения. Поскольку электроны имеют длину свободного пробега( 100мкм), что было больше толщины пленки (75мкм), процессы радиолиза совместно с релаксацией окрашивания скорее всего свидетельствует о том, что большая часть возбужденных молекул возвращается в основное состояние за счет рассеивания энергии возбуждения и поэтому влияние электронов на механические свойства меньше, чем протонов. Результаты, приведенные на рис.6а,б,в, демонстрируют явление окрашивания (потемнения) полиимидных образцов после их совместного облучения протонами и электронами (рис.6а), а также окрашивание образцов после раздельного облучения протонами (рис.6б).

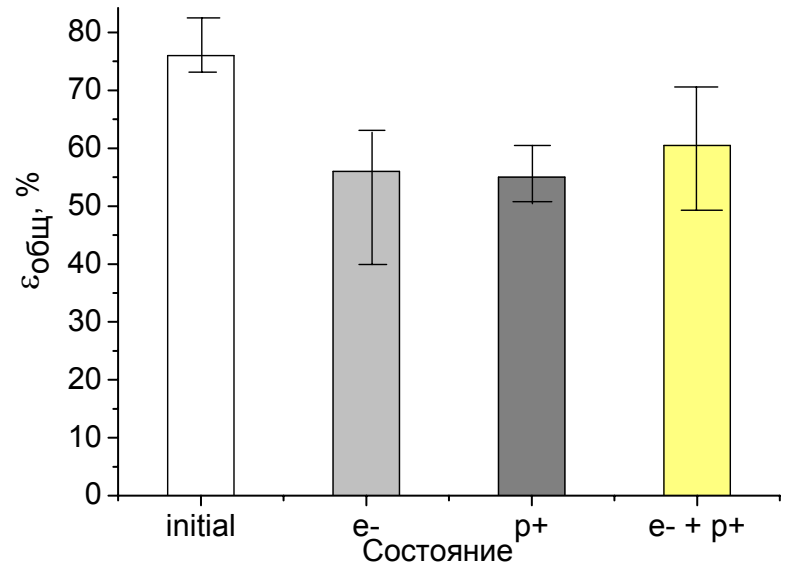

a

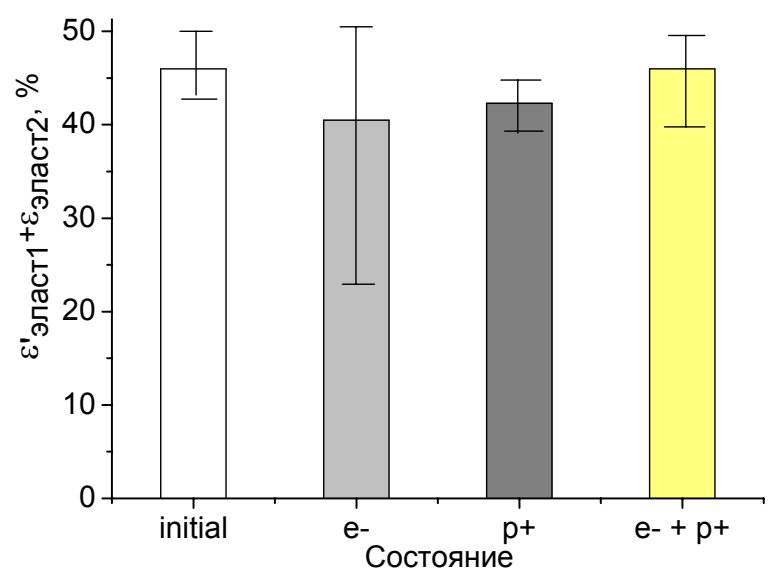

B

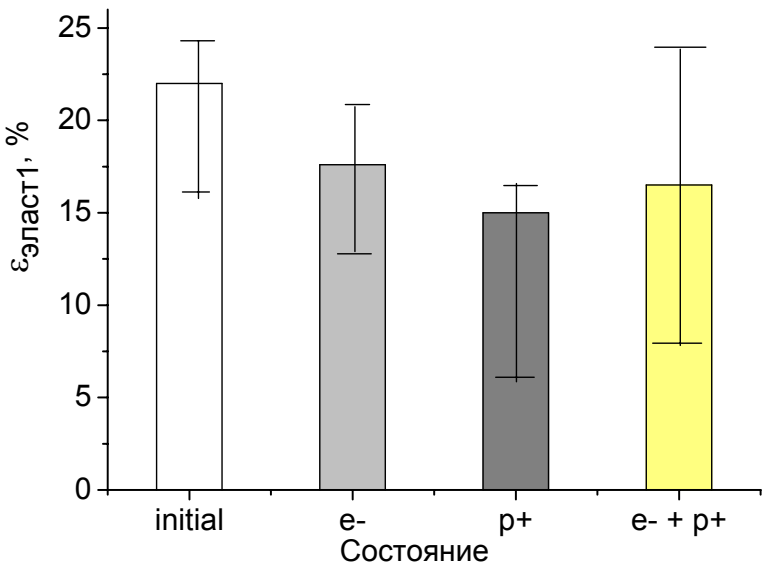

б

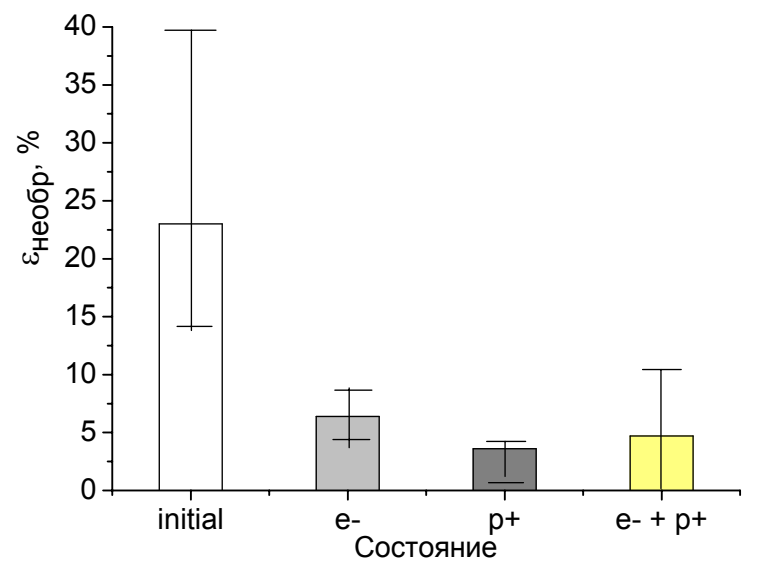

$\Gamma$

Рис.5. Средние значения суммарной деформации и ее составляющих образцов полиимидной пленки толщиной 75 мкм, деформированных при $\mathrm{T}=293$ в и исходном состоянии и после воздействия ФКП

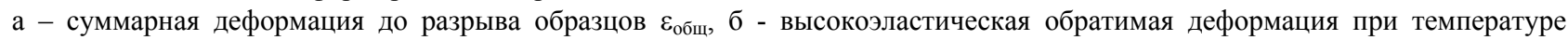

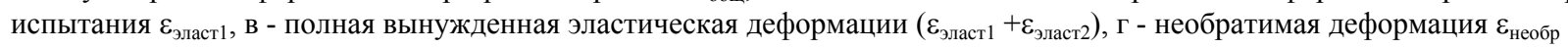

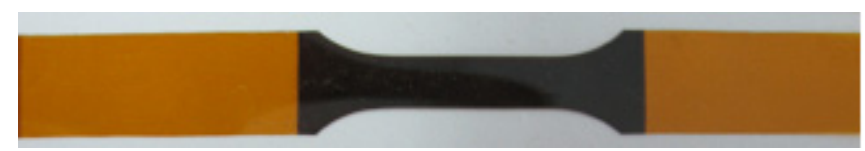

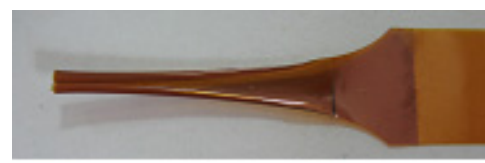

6

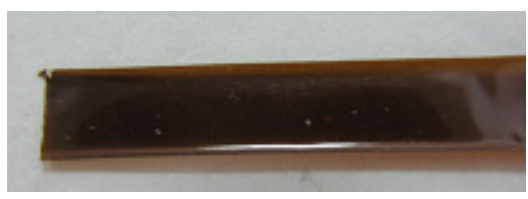

B
Рис.6. Внешний вид образцов

$\mathrm{a}$ - после совместного облучения протонами и электронами, б - после облучения протонами и деформации до разрушения, в - после облучения протонами и электронами и деформации до разрушения.

Видно, что после совместного облучения $\mathrm{p}^{+}$и $\mathrm{e}^{-}$(рис.6 а) образцы имели коричневую окраску, более 
насыщенную, чем после раздельного облучения протонами (рис.6 б). После деформирования до разрушения образцы, прошедшие облучение протонами, скручиваются (рис.6 б,в). Наибольшие макронапряжения возникали в образцах, облученных только протонами (рис.6б). Совместное облучение протонами и электронами существенно уменьшали макронапряжения, проявляющиеся при разрушении (рис.6в). Это согласуется с

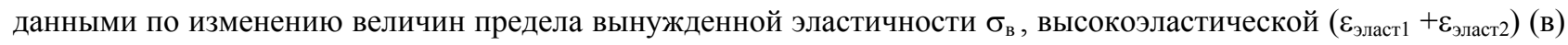
и необратимой деформации $\varepsilon_{\text {необр }}($ г) в образцах после воздействия ФКП по сравнению с исходными.

Следует особенно почеркнуть, что полученные в настоящей работе результаты хорошо согласуются с полученными ранее данными о высокой радиационной стойкости полиимидных материалов. Оказалось, что полиимиды являются радиационно устойчивыми материалами при значительных дозах облучения, соответствующих 100 эквивалентным годам пребывания КА на высоте Н=400км ( орбита МКС). Полиимидные пленки сохраняют ( в сравнении с исходными ) до 86-90\% величины напряжения разрушения $\sigma_{\mathrm{p}}$,

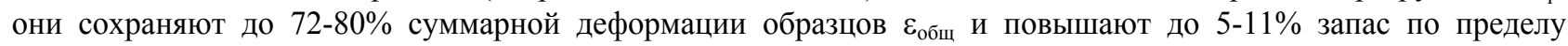
вынужденной эластичности. В литературе [1] предлагаются следующие механизмы, приводящие к повышению радиационной стойкости различных характеристик полиимидов:

1) Облучение полиимидов сопровождается конкурирующими процессами - разрывом макроцепей и межмолекулярным сшиванием. Снижение прочности, которое связано с процессами деструкции , компенсируется ее изменением за счет структурирования;

2) На разрыв связей бензольного кольца требуются большие энергетические затраты (следует отметить, что в мономере данного полиимида содержится максимальное число ароматических циклов);

3) Коллективная система т-электронов ароматических циклов способствует равномерному перераспределению избыточной энергии между всеми элементами цепи, которое также приводит к повышению радиационной стойкости полимера.

Основной причиной воздействия ФКП на механические свойства полиимидных пленок является: разрыв макроцепей и межмолекулярное сшивание. После воздействия факторов космоса, упрочнение полимера на пределе вынужденной эластичности, свидетельствует о получении в результате протекания указанных конкурирующих процессов, более жестко связанной структуры полимера (в сравнении с исходной), что при дальнейшем деформировании образцов понижает степень деформируемости и прочности образцов полиимида.

Однако важно отметить, что оценка изменения после воздействия ФКП величин, составляющих суммарную

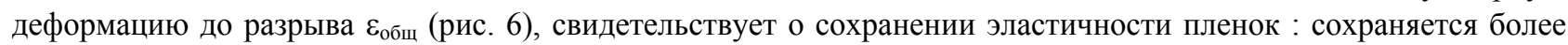
87-90\% вклада полной вынужденной эластической деформации, обусловленной переориентацией сегментов макромолекул. Основное уменьшение суммарной деформации происходит за счет сокращения вклада необратимой деформации, связанной с вязко-текучими процессами передвижения макромолекул в целом. Максимальное его сокращение происходит также после облучения протонами и составляет $80 \%$ от исходного значения.

\section{ВЫВОДЫ}

1.В настоящей работе проведено исследование механических свойств полиимидных пленок типа kарton-H толщиной 75 мкм производства КНР после воздействия ФКП (потоков протонов и электронов радиационных поясов Земли) при $293 \mathrm{~K}$ и скорости деформации $10^{-4} \mathrm{c}^{-1}$.

2. Получена серия диаграмм «напряжение-деформация» после воздействия ФКП. Установлено, что кривые деформации имеют две стадии: линейную и нелинейную.

3. Определены характеристики механических свойств полиимидных пленок: предел вынужденной эластичности

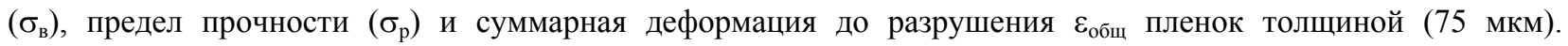

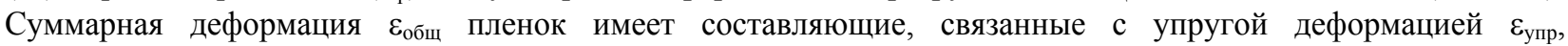

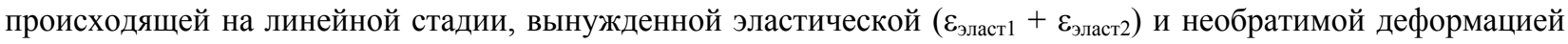

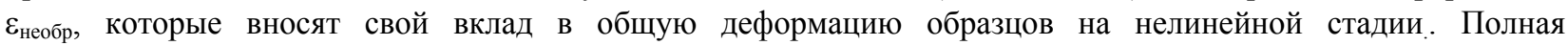
вынужденная эластическая деформация состоит из высокоэластической деформации $\varepsilon_{\text {эласт1 }}$ обратимой при температуре испытания, и задержанной эластической деформации $\varepsilon_{\text {эласт2. }}$.

4. Установлено, что облучение одними протонами, а также совместное воздействие протонами и электронами (энергией 160 кэВ и флюенсом частиц $10^{16}$ ч/см²) пленок полиимида толщиной 75 мкм, приводит в процессе их деформации при 293 К к упрочнению материала , т.е. к увеличению предела вынужденной эластичности $\sigma_{\text {в }}$ (на 5-11\%), к снижению предела прочности $\sigma_{\mathrm{p}}$ ( на 10-14 \%) и уменьшению суммарной степени деформации $\varepsilon_{\text {общ }}($ на 20-28\%). Максимальное влияние на все механические характеристики полиимидных пленок оказывает облучение одними протонами.

5. Экспериментально обнаружено, что вклад общей вынужденной эластической деформации $\left(\varepsilon_{\text {эласт1 }}+\varepsilon_{\text {эласт2 })}\right.$ облученной пленки полиимида сохраняется практически на том же уровне, что и в исходном состоянии. Наибольшее снижение (на 80\%) демонстрирует величина вклада необратимой деформации полиимидных пленок.

6. Сохранение высокого уровня предела вынужденной эластичности, а также высокой деформируемости пленок 
полиимида после значительных доз облучения корпускулярными частицами (потоком протонов и электронов), имеет важное научное и прикладное значение при создании космических аппаратов новых поколений с временами жизни 5-20 лет.

\section{СПИСОК ЛИТЕРАТУРЫ}

1. Bessonov M.I., Koton M.M., Kudryavtsev V.V., Layus 1.A. Polyimidyu - klass termostoykih polymerov [Polyimides - class of heat-resistant polymers].-L.: Nauka, 1984.-328 p. (in Russian).

2. Lototskaya V.A., Yakovenko L.F., Aleksenko E.N., Abraimov V.V., Wen Zhu Shao Low temperature deformation and strength of polyimide films due to thickness and deformation speed //East.Eur.J.Phys.-2017.-Vol.4. - No2. - P.44-52.

3. Volikova L.M., Chernetskiy V.K. Nizkotemperaturnaya pristavka k razryvnoy mashine 1231 Y10 [Low temperature unit to tensile testing mashine] sb. Prikladnoe kriogennoe i vakuumnoe materialovedenie [Applied cryogenic and vacuum material science] pod red. Lavrentev F.F. -Kyiv: Nauk. dumka, 1991 - P. 137-143 (in Russian).

4. Abraimov V.V., Negoda A.A., Zavalishin A.P., Kolybaev L.K. Kompleksnayu imitatsiya faktorov kosmicheskogo prostranstva [Complex imitation of space factors ]// Kosmichna nauka i technologiya [Space Science and Technology].-1995.- Vol. 1. No 2-6. - P.76-80 (in Russian).

5. Abraimov V.V., Agashkova N.N., Bone L., Budnyak I.V., Velichko N.I., Krevsun A.V., Kostenko V.I., Lura F., Markus A.M. Kompleksnye issledovaniya fiziko-mechanicheskih svoystv materialov svetopogloshchayushchih pokrytiy kosmicheskih apparatov proektov "Mars-96" I "Regata" pod vozdeystviem factorov kosmicheskogo prostranstva [Complex researches of physico-mechanical properties of materials of light-absorbing coverings of space vehicles of projects «Mars -96» and "Regatta" under influence of space factors ] // Kosmichna nauka i technologiya [Space Science and Technology].-1995.-Vol.1. -No.1.P.57-68 (in Russian).

6. Abraimov V.V., Lototskaya V.A., Zaritskiy I.P., Saltevskiy G.I. Vliyanie factorov kosmosa (nizkih temperatur, zaatmosfernogo solntsa, potokov protonov I elektronov) na mehanicheskie svoystva nekotoryh polimerov [Influence of space factors (low temperatures, the exoatmospheric sun, streams of protons and electrons) on mechanical properties of some polymers] //Abstr. 55 Internat. Conf. "Aktual'nye problemy prochnosti” [Actual strength problems], 9-13 april 2014.- Kharkov, Ukraine.- P. 158 (in Russian).

7. Abraimov V.V., Bocharov K.Sh., Danovskiy V.V., Udovenko V.F. Vliyanie VUF - izlucheniya na deformatsionnye i prochnostnue svoystva polietilena $\mathrm{v}$ intervale temperatur 200-350 K [Influence of VUV-radiation on deformation and strength properties of polythene in the temperature interval 200-350 K] // sb. Radatsionnaya stoykost' organicheskih materialov $\mathrm{v}$ usloviyah kosmosa [Radioresistance of organic materials under space conditions].- M.,NIITEHIM, 1989.- Vyp.8.- P.21-25 (in Russian).

8. Verkin B.I., Udovenko V.F. Abraimov V.V., Bocharov K.Sh. Vliyanie elekteromagnitnogo izlucheniya v oblasti 0,01-25 mkm na mehanicheskie svoystva nekotoryh polimernyh materialov [Influence of electromagnetic radiation in the field of 0,01-25 microns on mechanical properties of some polymeric materials] // sb.Kosmichna nauka i technika [Space science and technology ].- Kyiv: Nauk. dumka, 1988 .-Vyp.3.-P.54-57 (in Russian).

9. Abraimov V.V., Bocharov K.Sh., Galuza A.I., Udovenko V.F. Vliyanie elekteromagnitnogo izlucheniya v oblasti 5-2500 nm na mehanicheskie I opticheskie svoystva nekotoryh polimernyh materialov [Influence of electromagnetic radiation in the field of 5-2500 nanometers on mechanical and optical properties of some polymeric materials] // sb. Radatsionnaya stoykost' organicheskih materialov $\mathrm{v}$ usloviyah kosmosa [Radioresistance of organic materials under space conditions].M.,NIITEHIM,1989.- Vyp.10.-P.23-30 (in Russian).

10. Abraimov V.V., Bocharov K.Sh., Danovskiy V.V., Udovenko V.F. Issledovanie vozdeystviya elektromagvitnogo izlucheniya v oblasti 5-2300 nm na fiziko-mehanicheskie svoystva polimernyh materialov [Investigation of physical-mechanical properties of polymeric materials under influence of electromagnetic radiation in the field of 5-2500 nanometers] // sb. Prikladnoe kriogennoe i vakuumnoe materialovedenie [Applied cryogenic and vacuum material science] pod red. Lavrentev F.F. -Kyiv: Nauk. dumka, 1991 - P. 103-109 (in Russian). 